\title{
Linking Centennial Surface Warming Patterns in the Equatorial Pacific to the Relative Strengths of the Walker and Hadley Circulations
}

\author{
JIAN MA AND JIN-YI YU \\ Department of Earth System Science, University of California, Irvine, Irvine, California
}

(Manuscript received 19 February 2014, in final form 13 May 2014)

\begin{abstract}
This study analyzes representative concentration pathway 4.5 projections by 18 models from phase 5 of the Coupled Model Intercomparison Project to show that surface warming patterns in the equatorial Pacific during the twenty-first century (centennial warming) are influenced by the relative strengths of the Walker and Hadley circulations. The stronger the Hadley (Walker) circulation is, the greater the surface warming in the central Pacific (CP) [eastern Pacific (EP)]. The EP warming is associated with the Bjerknes feedback, while the CP warming is associated with the wind-evaporation-sea surface temperature feedback. This atmospheric circulation influence on the centennial warming is similar to that found for the EP and CP El Niño. This suggests a methodology to constrain the estimate of the projected surface warming patterns in the equatorial Pacific using recent El Niño activity. The constraint indicates that the "most likely" centennial warming patterns have a maximum in the EP and are $39 \%$ weaker than the warming projected by the 18-model mean. The most-likely projection also shows alternating stronger and weaker warming in the subtropical North Pacific, which is not predicted by the 18-model mean projection. Nevertheless, the two projections agree on the minimum warming in the southeastern subtropical Pacific.
\end{abstract}

\section{Introduction}

As a heat engine of global atmosphere, the equatorial Pacific Ocean has profound impacts on precipitation, circulation, and energy transport in both climate variability ( $\mathrm{Lu}$ et al. 2008) and change (Held and Soden 2006; Ma et al. 2012; Ma and Xie 2013). As a response to increases in greenhouse gases and changes in aerosol concentrations, the ensemble-mean projections of surface ocean warming from phases 3 and 5 of the World Climate Research Programme's (WCRP's) Coupled Model Intercomparison Project (CMIP) both show a peak in the equatorial Pacific (Liu et al. 2005; Xie et al. 2010; Ma and Xie 2013), which is often characterized as El Niño-like. However, significant differences exist in the projections made within the CMIP3 or CMIP5 ensemble and between them (Ma and Xie 2013). One of the intermodel uncertainties is in the location of the peak equatorial warming. While some models project warming extending into the central Pacific (e.g., the

Corresponding author address: Jian Ma, Department of Earth System Science, 1101A Croul Hall, University of California, Irvine, Irvine, CA 92697.

E-mail: tonyj.ma@gmail.com
CMIP3 ensemble mean), others indicate warming confined more to the eastern Pacific (e.g., the CMIP5 ensemble mean; Ma 2012), or even resemble La Niña (e.g., Vecchi et al. 2008).

In fact, the regional patterns of surface warming can significantly affect rainfall change over tropical oceans via atmospheric circulation change (Xie et al. 2010; Ma and Xie 2013; Huang et al. 2013). Following the "warmer get wetter" paradigm, annual rainfall increases where sea surface warming exceeds the tropical mean, and vice versa. Uncertainty in surface ocean warming patterns is an important source for uncertainties in future projections of rainfall (explaining $1 / 3$ of the intermodel variability) and atmospheric circulation (explaining $4 / 5$ of the intermodel variability; Ma and Xie 2013). Moreover, surface ocean warming patterns significantly affect the Hadley circulation in both CMIP3 and CMIP5 models, resulting in robust weakening north of the equator and weak but highly uncertain change near and south of the equator (Ma et al. 2012; Ma and Xie 2013). These large uncertainties urge us to find methods to constrain the estimate of the future projections for surface ocean warming patterns and reduce the intermodel uncertainty. However, as the currently available observation record is too short for the anthropogenic global warming signal to stand out 
from natural variability, there are a number of ongoing efforts to achieve this goal via alternative approaches.

Existing observational datasets are adequate to examine the interannual variability in the equatorial $\mathrm{Pa}$ cific. There may be ways to reduce the uncertainty of the climate models projections using their skill in simulating the interannual variability. Two types of interannual sea surface temperature (SST) variability are suggested to exist in the tropical Pacific (Larkin and Harrison 2005; Yu and Kao 2007; Ashok et al. 2007; Kao and Yu 2009; Kug et al. 2009), with one having its anomalies centered in the eastern Pacific, referred to as the eastern Pacific (EP) type, and the other in the central Pacific, referred to as the central Pacific (CP) type (Yu and Kao 2007; Kao and Yu 2009). The CP El Niño has occurred more frequently in recent decades (Ashok et al. 2007; Kao and Yu 2009; Yeh et al. 2009; Lee and McPhaden 2010; Yu et al. 2012). The dominance of the EP or CP type of El Niño has been linked to the relative strengths of the Walker and Hadley circulations (Yu et al. 2012). By analyzing the relationship between SST variations in the tropical Pacific and sea level pressure (SLP) variations over the extratropical Pacific during 1979-2009, they showed that extratropical SLP variations has exerted a stronger influence on SST variations in the tropical central Pacific since 1990 and caused the shift of El Niño from a predominantly EP type before 1990 to a predominantly CP type afterward. The increased influence of the extratropical influences on tropical central Pacific SST variations was suggested to be related to a strengthening of the Hadley circulation. The stronger the mean Hadley circulation is, the more CP El Niño events occur. This recent view suggested that the CP El Niño develops through a mechanism dependent on the atmospheric forcing originating within the sinking branch of the Hadley circulation over the subtropical high. The windevaporation-SST (WES) feedback mechanism of Xie and Philander (1994) has been suggested as a major process to extend the influence of the subtropical atmospheric forcing into the central equatorial Pacific (Vimont et al. 2009) via the so-called seasonal footprinting mechanism (Vimont et al. 2001, 2003). The seasonal footprinting mechanism was further suggested to play an important role in exciting the CP El Niño ( $\mathrm{Yu}$ and Kim 2011). The zonal advective feedback involving ocean dynamics is also at work (Kug et al. 2009). As for the EP El Niño, it develops through a Bjerknes feedback mechanism (Bjerknes 1969) that invokes the interaction between the equatorial thermocline and the Walker circulation. The stronger the Walker circulation is, the more EP El Niño events occur. These recent studies relate the EP El Niño to the Walker circulation and the CP El Niño to the Hadley circulation (Yu et al. 2010; Yu et al. 2012).
Here, we present evidence that a similar relationship exists between the relative Walker and/or Hadley circulation strength and anthropogenic surface warming patterns in the equatorial Pacific. This similarity suggests a way to use the observed El Niño activity to identify the most-likely warming patterns in the twentyfirst century Pacific. The technique explored in this study enables us to reduce the uncertainty in the CMIP5 model projections and to determine a "most likely" projection.

The rest of the paper is organized as follows. Section 2 describes model output, observational data, and methods used in this study. Interannual variability, its relationship with the mean Walker and Hadley circulations simulated in the CMIP5 models, and comparisons with observations are presented in section 3. Section 4 examines mechanisms controlling the centennial equatorial Pacific warming patterns and roles of mean Walker and Hadley circulations and explores methodology to constrain the estimate of the climate projections with interannual variability, followed by conclusions and discussion in section 5 .

\section{Data and methods}

Representative concentration pathway (RCP) 4.5 simulations produced by 18 CMIP5 models are used in this study (models and expanded names are provided in Table 1). These models provide various lengths of simulations with the future radiative forcing stabilized at $4.5 \mathrm{~W} \mathrm{~m}^{-2}$ in 2100 (Thomson et al. 2011). We analyze one realization ("r1i1p1") for each model during the period 2006-98. The Met Office Hadley Centre Sea Ice and SST dataset (HadISST) (Rayner et al. 2003) is used to provide SST observations. This monthly dataset has a spatial resolution of $1^{\circ} \times 1^{\circ}$ and covers the period 1870-2012.

Following Ma et al. (2012), the strength of the Hadley circulation is represented by the difference of the $500-\mathrm{hPa}$ meridional mass streamfunction between $10^{\circ}-20^{\circ} \mathrm{N}$ and $10^{\circ}-20^{\circ} \mathrm{S}$. The strength of the Walker circulation is calculated as the difference between the $250-\mathrm{hPa}$ velocity potential in the eastern Pacific $\left(15^{\circ} \mathrm{S}-15^{\circ} \mathrm{N}, 90^{\circ}-140^{\circ} \mathrm{W}\right)$ and that in the western Pacific $\left(15^{\circ} \mathrm{S}-15^{\circ} \mathrm{N}, 110^{\circ}-160^{\circ} \mathrm{E}\right)$.

We also need to calculate the occurrence frequency of the two types of El Niño. To do this, SST anomalies are first computed by removing the trend and monthly-mean climatology. An EP index and a CP index are constructed from the detrended SST anomalies to represent the activities of the EP El Niño and CP El Niño, respectively, using a regression-empirical orthogonal function (EOF) method (Kao and Yu 2009). The regression-EOF method also reveals the SST anomaly patterns of the EP and CP El Niño in the HadISST and simulated by the 18 CMIP5 
TABLE 1. CMIP5 models and their expansions.

\begin{tabular}{ll}
\hline \multicolumn{1}{c}{ Model } & \\
\hline ACCESS1.0 & Australian Community Climate and Earth System Simulator, version 1.0 \\
BCC_CSM1.1 & Beijing Climate Center, Climate System Model, version 1.1 \\
CanESM2 & Second Generation Canadian Earth System Model \\
CCSM4 & Community Climate System Model, version 4 \\
CNRM-CM5 & Centre National de Recherches Météorologiques Coupled Global Climate Model, version 5 \\
GFDL CM3 & Geophysical Fluid Dynamics Laboratory Climate Model, version 3 \\
GFDL-ESM2G & Geophysical Fluid Dynamics Laboratory Earth System Model with Generalized Ocean Layer Dynamics \\
& (GOLD) component \\
HadGEM2-CC & Hadley Centre Global Environment Model, version 2-Carbon Cycle \\
HadGEM2-ES & Hadley Centre Global Environment Model, version 2-Earth System \\
INM-CM4 & Institute of Numerical Mathematics Coupled Model, version 4.0 \\
IPSL-CM5A-LR & L'Institut Pierre-Simon Laplace Coupled Model, version 5A, low resolution \\
IPSL-CM5A-MR & L'Institut Pierre-Simon Laplace Coupled Model, version 5A, mid resolution \\
MIROC5 & Model for Interdisciplinary Research on Climate, version 5 \\
MIROC-ESM & Model for Interdisciplinary Research on Climate, Earth System Model \\
MIROC-ESM-CHEM & Model for Interdisciplinary Research on Climate, Earth System Model, Chemistry Coupled \\
MPI-ESM-LR & Max Planck Institute Earth System Model, low resolution \\
MRI-CGCM3 & Meteorological Research Institute Coupled Atmosphere-Ocean General Circulation Model, version 3 \\
NorESM1-M & Norwegian Earth System Model, version 1 (intermediate resolution) \\
\hline
\end{tabular}

models. An El Niño or La Niña event of the EP (CP) type is identified if the 3-month-smoothed EP (CP) index is greater than \pm 0.8 standard deviation for more than 4 months. The EP-to-CP frequency ratio is defined as the total number of El Niño and La Niña events of the EP type divided by the total number of events of the CP type. We found that the EP-to-CP ratio is not sensitive to the choice of the standard deviation threshold. For the sake of discussion, the term El Niño is used in the rest of the paper to mean both El Niño and La Niña.

\section{Interannual variability in the CMIP5 RCP4.5 simulations}

We first illustrate in Figs. 1-3 the abilities of the 18 CMIP5 RCP4.5 simulations to reproduce the observed SST anomaly patterns and intensity for the EP and CP types of El Niño. The EP and CP patterns are obtained by using the regression-EOF method (Kao and $\mathrm{Yu}$ 2009). Calculated from the HadISST (Rayner et al. 2003), the observed EP type of El Niño (Fig. 1a) shows positive SST anomaly concentrating in the eastern equatorial Pacific and extending to the west coast of South America and negative anomaly in the surrounding area of the subtropical and western equatorial $\mathrm{Pa}$ cific. On the other hand, the CP type of El Niño (Fig. 1b) has positive SST anomaly centered in the central equatorial Pacific and extending to the West Coast of the United States and negative anomaly in the northwestern and southwestern subtropical Pacific. The EOF variance explained by the CP El Niño (34\%) is slightly larger than that by the EP El Niño (29\%).
In general, most models can grasp the SST patterns and intensity for both the EP and CP types of El Niño from the observations, despite that the variances explained in them are about $1 / 3-2 / 3$ of those in the observations. On average, agreement with the observations is higher for the CP type (Fig. 3) than for the EP type (Fig. 2) of El Niño, with ensemble-mean spatial correlation coefficients of 0.77 and 0.66 , respectively. Taking the ensemble-mean values as thresholds, models can be classified according to their correlations with the observations. Models that fail to pass the threshold for the EP type of El Niño include the CanESM2, INM-CM4, IPSLCM5A-LR, IPSL-CM5A-MR, MIROC-ESM-CHEM, and MIROC-ESM, and the CP-failure models are the HadGEM2-ES, INM-CM4, MIROC-ESM-CHEM, MIROC-ESM, and MRI-CGCM3.

We then examine whether the observed tendency for the relative strengths of the time-mean Walker $(\bar{W})$ and Hadley $(\bar{H})$ circulations to determine the dominance of the EP or CP type of El Niño (Yu et al. 2012) exists in the RCP4.5 simulations. Figure 4 shows the relationship between the EP-to-CP frequency ratio and the relative circulation strength $(\bar{W} / \bar{H})$ among the CMIP5 models. The frequency ratio is less than 1 for 14 out of 18 models during 2006-98, which means the CP El Niño is projected to occur more frequently in the twenty-first century by most of the CMIP5 models. A general tendency is found between the frequency ratio and the relative circulation strength simulated by the models: the stronger the Walker (Hadley) circulation is in a model, the more frequently the EP $(\mathrm{CP})$ El Niño is projected to occur. The correlation coefficient $r$ between these two 

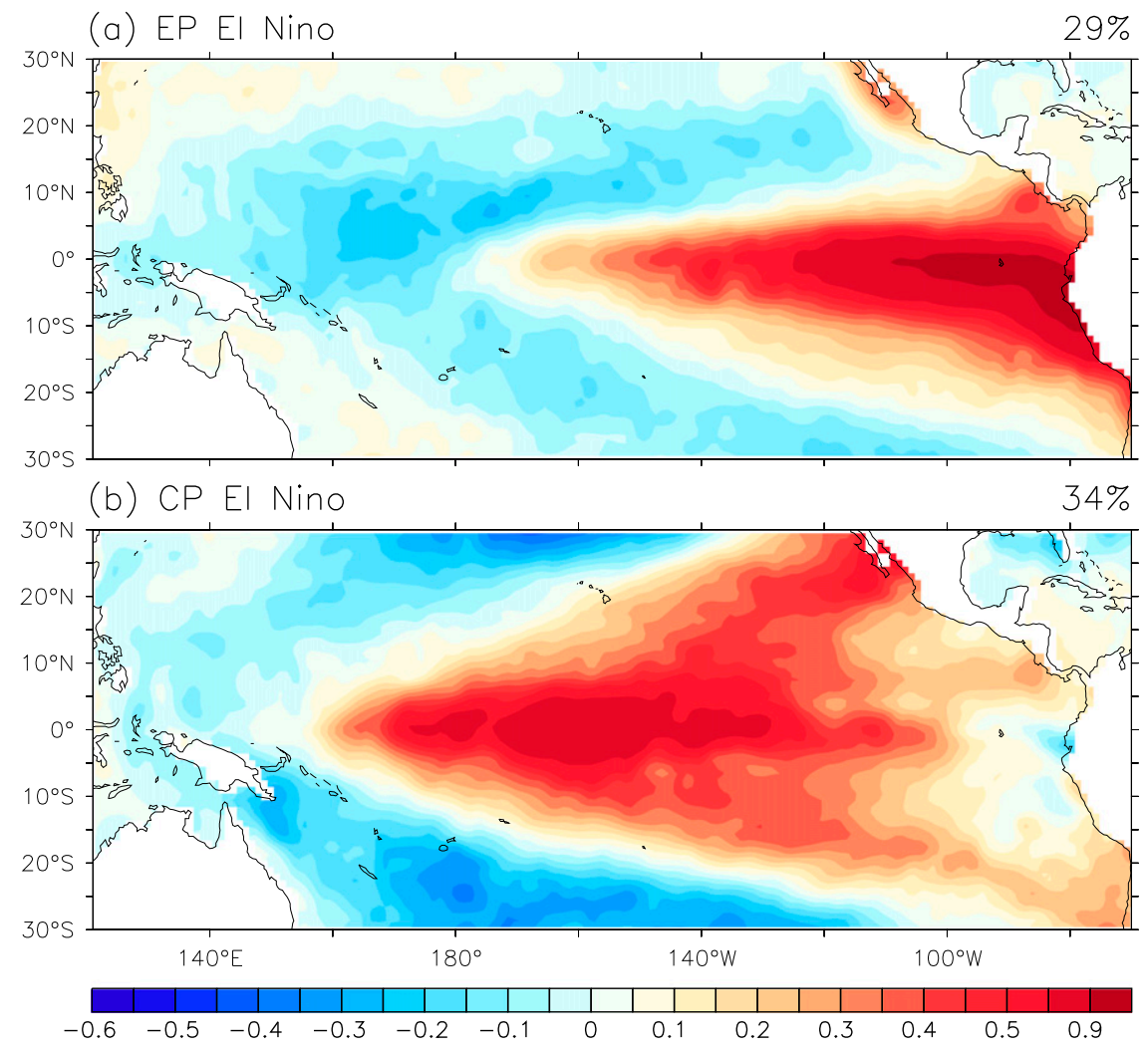

FIG. 1. Observed SST patterns and intensity of the (a) EP and (b) CP types of El Niño with the EOF variances they explain calculated from the HadISST.

ratios is 0.38 among the 18 CMIP5 models, and the regression passes the $85 \%$ significance level. Figure 4 indicates that the influence of the relative strengths of the Walker and Hadley circulations on the selection of the El Niño type exists not only in the observations but also in the simulations. This is a useful fact that can be utilized to link the observations to the CMIP5 projections.

\section{Centennial warming patterns in the equatorial Pacific}

This section examines whether or not the relative circulation strength can also influence the centennial warming patterns in the equatorial Pacific, and explores possibility to use this relationship to constrain the estimate of the climate projections with observed interannual variability. Figure 5 shows the twenty-first century SST warming patterns produced by the 18 CMIP5 RCP4.5 simulations. This centennial warming is defined as the SST difference between the last and first 10 years of the simulations (i.e., 2089-98 minus 2006-15). To highlight the spatial variations of the warming, the tropical $\left(20^{\circ} \mathrm{S}-\right.$ $20^{\circ} \mathrm{N}$ ) Pacific mean is subtracted from the SST difference. As such, the positive values shown in Fig. 5 represent stronger warming (than the tropical Pacific mean) and negative values represent weaker warming. To make sure that we are comparing only the spatial structures of the warming among the models, the values shown in Fig. 5 have been further normalized by the tropical Pacific mean warming of each model. We refer to this normalized pattern as the relative centennial warming $T^{*}$. As the aforementioned warmer-get-wetter mechanism explains, $T^{*}$ is essential for regional changes in tropical cyclone activity (Vecchi and Soden 2007), precipitation (Xie et al. 2010; Ma and Xie 2013), and atmospheric circulation (Ma et al. 2012; Ma and Xie 2013).

In Fig. 5, the most noticeable agreement among the models is that weaker warming resides in the southeastern subtropical Pacific and stronger warming appears in the subtropical North Pacific. This interhemispheric asymmetry is consistent with other studies on global warming patterns (e.g., Xie et al. 2010; Ma et al. 2012; Ma and Xie 2013). In the equatorial Pacific, the centennial warming patterns vary from model to model. While most models produce stronger warming in the eastern Pacific, the warming in some models is confined exclusively to the South American coastal region (e.g., ACCESS1.0) and extends all the way to the central Pacific in others 

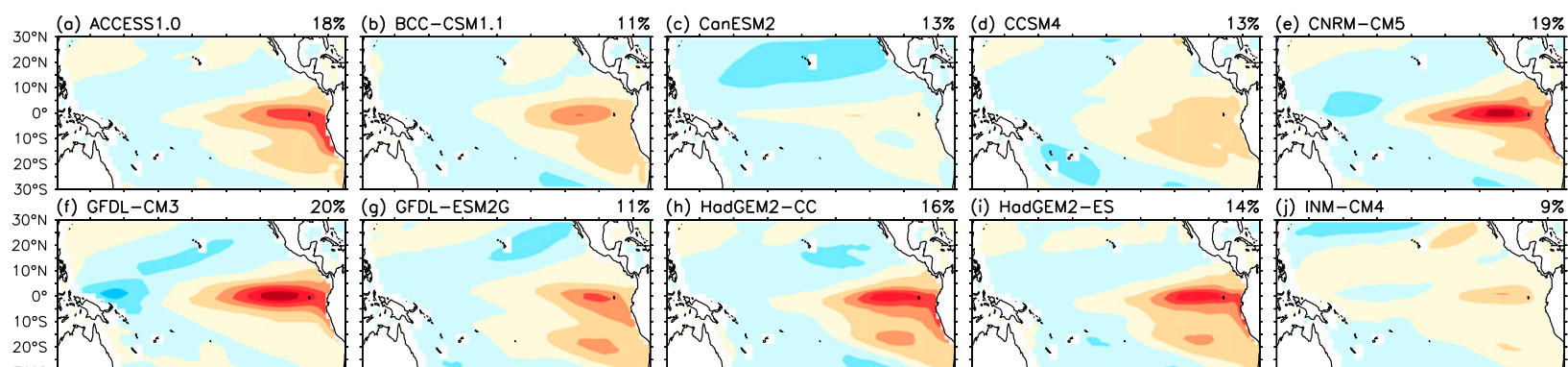

$30^{\circ} \mathrm{N}$ (k) IPSL-CM5A-LR, $10 \%$
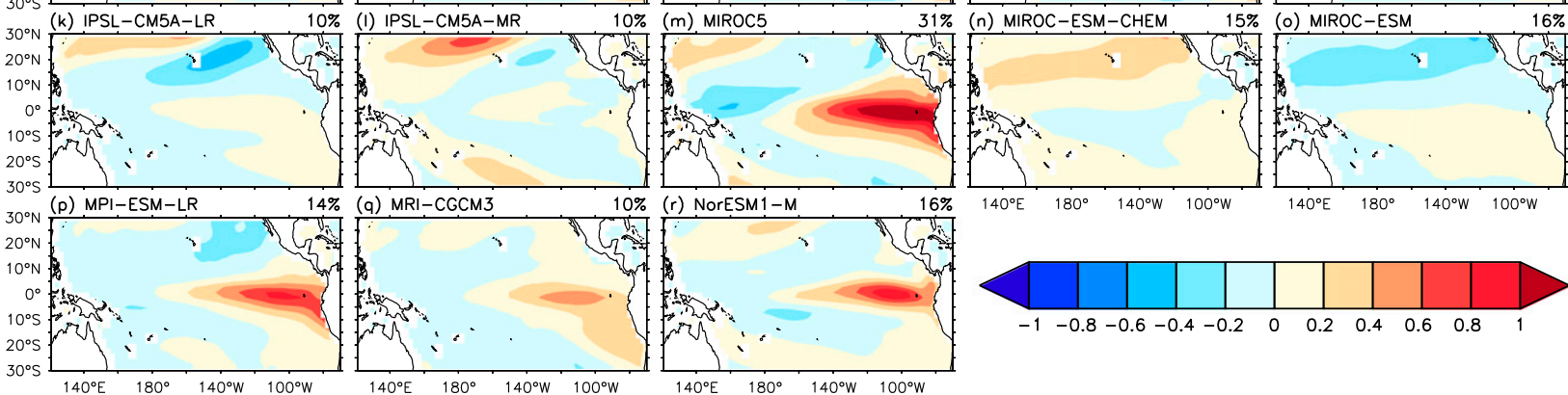

FIG. 2. SST patterns and intensity of the EP type of El Niño simulated by the 18 CMIP5 models along RCP4.5, with the EOF variance it explains for each model.

(e.g., GFDL CM3). In the central Pacific, there are also models that produce strong negative values (e.g., MIROC5) rather than positive $T^{*}$. Figure 5, therefore, indicates that there are two major centers of $T^{*}$ in the equatorial Pacific: one located in the eastern Pacific and the other located in the central Pacific. To further demonstrate this conclusion, we also performed an intermodel EOF analysis (Fig. 6) on the relative centennial warming in the equatorial Pacific following the method of Ma (2012) and Ma and Xie (2013). The first leading EOF mode (shown in Fig. 6a) is characterized by the equatorial peak warming, explaining $38 \%$ of the total intermodel variance; and the second mode (Fig. 6b) represents zonal asymmetry along the equator (warming peak in the $\mathrm{EP}$ or in the $\mathrm{CP}$ ), explaining $24 \%$ of the total variance. Thus, the twenty-first century surface ocean warming patterns revealed by the 18

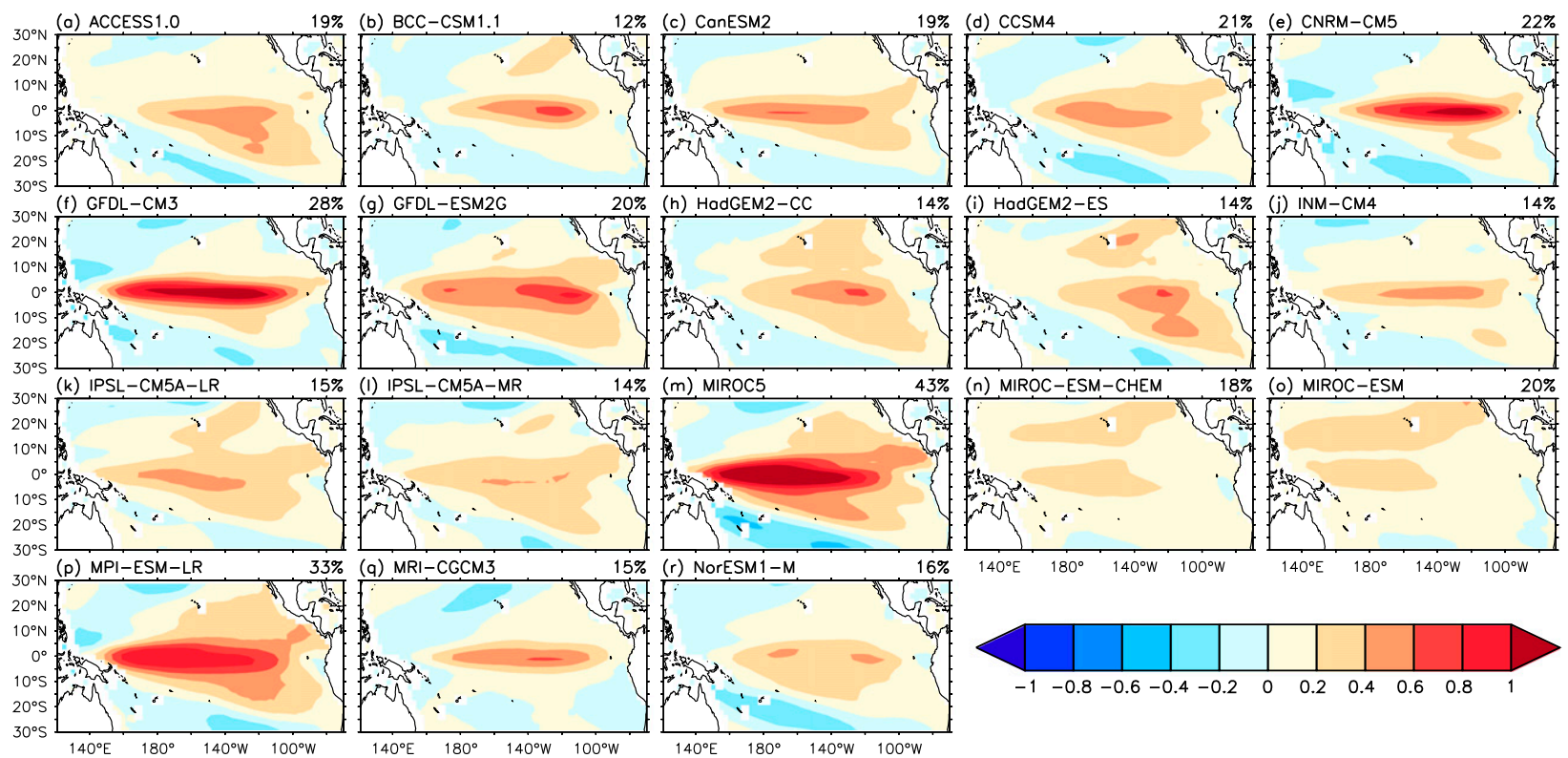

FIG. 3. As in Fig. 2, but for the CP type of El Niño. 


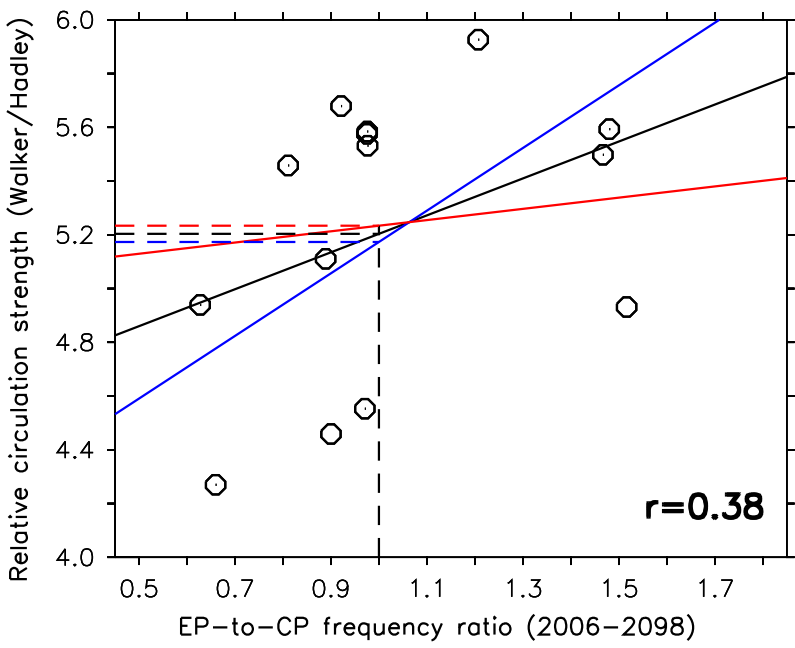

FIG. 4. Relation between the frequency ratio of EP and CP El Niño events and the relative strengths of the Walker and/or Hadley circulations $\left(10^{-5} \mathrm{~m}^{2} \mathrm{~kg}^{-1}\right)$ calculated from the RCP4.5 simulations (2006-98) produced by the 18 CMIP5 models. The correlation coefficient between the two variables is shown on the bottom right. Dashed lines mark the observational estimation of the EP-to-CP frequency ratio (1.0) from the HadISST and the corresponding value of the relative circulation strength $\left[(5.2 \pm 0.03) \times 10^{-5} \mathrm{~m}^{2} \mathrm{~kg}^{-1}\right]$ determined by the regression line. Colored lines (colored dashed lines) indicate the uncertainty (standard deviation) of the regression (estimation).

CMIP5 models resemble the pattern of EP El Niño in some projections but the pattern of CP El Niño in others.

We next examine if the projected centennial warming in the $\mathrm{EP}$ and $\mathrm{CP}$ regions can also be linked, respectively, to the Bjerknes and WES feedback mechanisms, as is the case for the EP and CP El Niño. We look into the relationships among the simulations of $T^{*}$ with the centennial change in sea surface height $(\Delta \mathrm{SSH}$; difference between 2089-98 and 2006-15) for the Bjerknes feedback mechanism because it can reflect thermocline fluctuation (Bjerknes 1969), and with the change in surface wind speed ( $\triangle$ WSP) for the WES feedback mechanism, since wind speed is a strong factor of surface evaporation (Xie and Philander 1994). Note that $\Delta$ WSP may also reflect the zonal advective feedback that may be at work. These relationships are examined for the Niño-3 $\left(5^{\circ} \mathrm{S}-5^{\circ} \mathrm{N}, 90^{\circ}-150^{\circ} \mathrm{W}\right.$; representing the EP) and Niño-4 $\left(5^{\circ} \mathrm{S}-5^{\circ} \mathrm{N}, 160^{\circ} \mathrm{E}-150^{\circ} \mathrm{W}\right.$; representing the $\left.\mathrm{CP}\right)$ regions. In the Niño-3 region, the relationship between $T^{*}$ and $\Delta \mathrm{SSH}$ is found to be strong $(r=0.86$; Fig. 7a) but that between $T^{*}$ and $\Delta$ WSP weak $(r=-0.38$; Fig. 7b), indicating that the Bjerknes feedback mechanism dominates the centennial warming over the EP region (beyond the $99.9 \%$ significance level). In contrast, for the Niño-4 region, the correlation of $T^{*}$ with $\Delta \mathrm{WSP}(r=$ -0.57 ; Fig. $7 \mathrm{~d})$ is higher than with $\Delta \mathrm{SSH}(r=0.22$; Fig. 7c), suggesting that the WES feedback plays the dominant role in producing relative SST changes in the $\mathrm{CP}$ region (with the $99 \%$ significance level). In addition, the Bjerknes feedback represented by $\Delta \mathrm{SSH}$ in the Niño-3 region is associated with change of the Walker circulation, indicated by a high intermodel correlation coefficient of -0.45 . Similarly, the WES feedback represented by $\Delta$ WSP in the Niño-4 region is associated
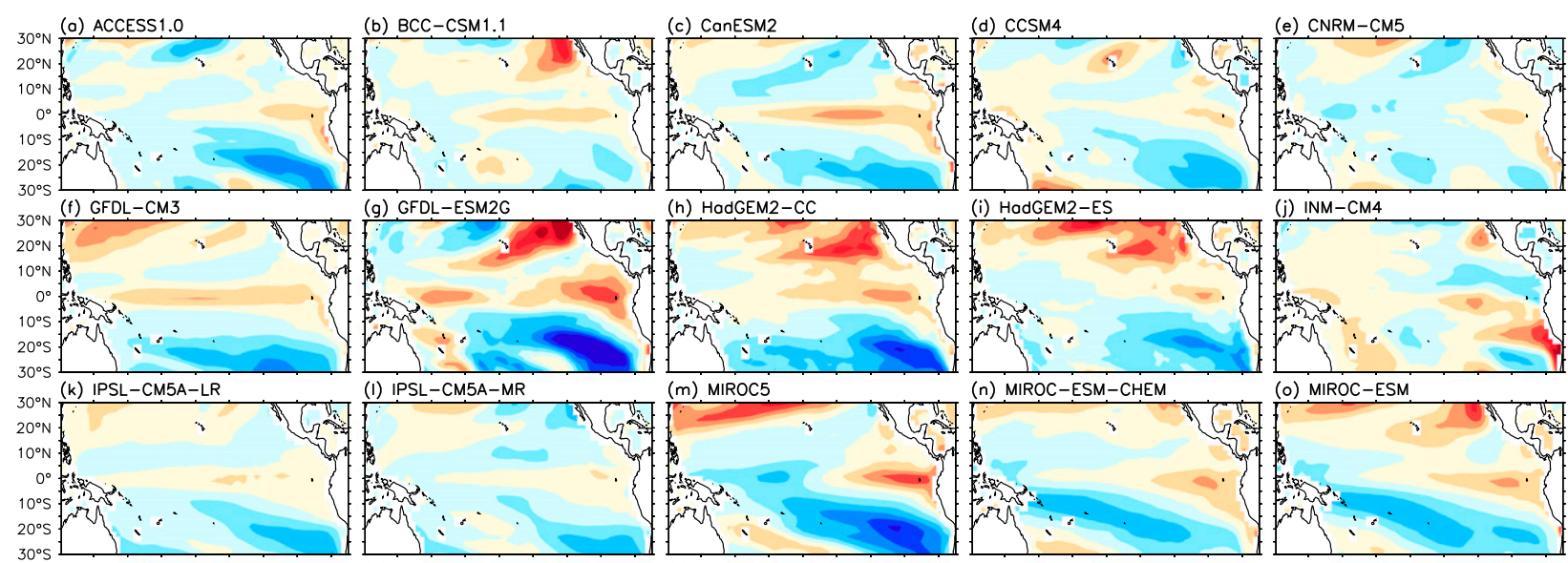

(m) MIROC5

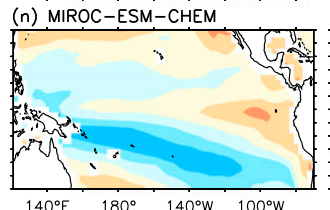

(o) MIROC-ESM
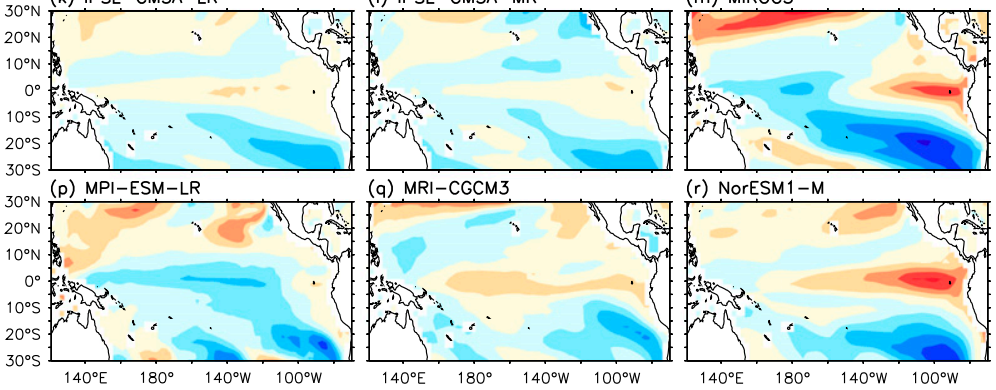

FIG. 5. Centennial surface warming patterns $\left(\mathrm{K} \mathrm{K}^{-1}\right)$ in the tropical Pacific projected by the 18 CMIP5 RCP4.5 simulations. The warming is calculated as the difference between the decadal means for 2089-98 and 2006-15. The values shown are the deviations from the tropical $\left(20^{\circ} \mathrm{S}-20^{\circ} \mathrm{N}\right)$ Pacific mean of each model and have been scaled by this mean. 
(a) Inter-model EOF 1 $38 \%$

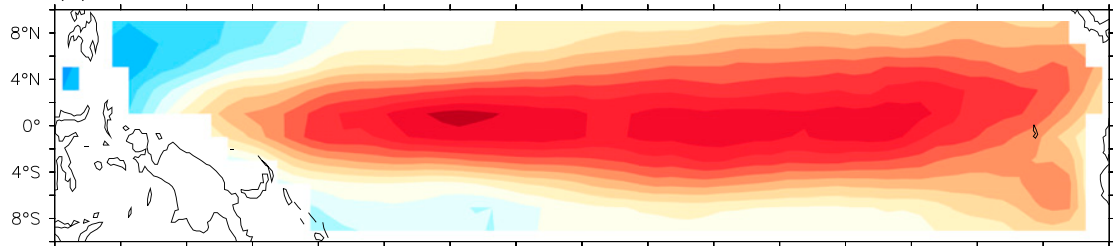

(b) Inter-model EOF 2

$24 \%$

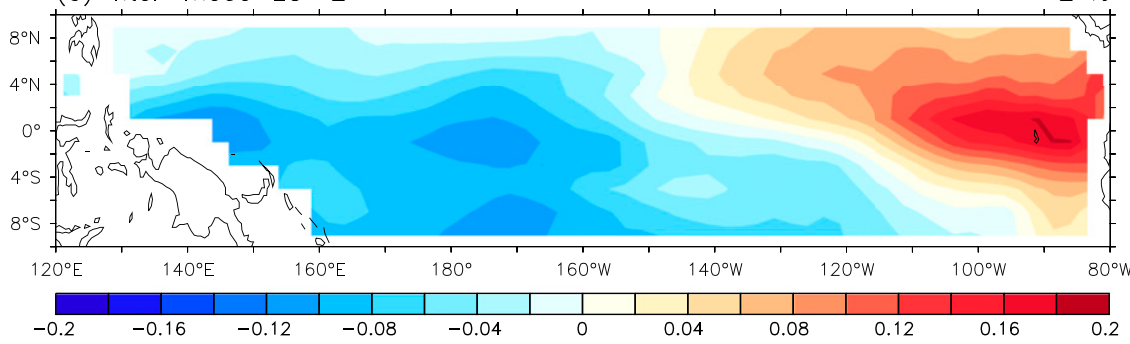

FIG. 6. Leading EOF modes for intermodel variability of the relative centennial warming in the equatorial Pacific $\left(10^{\circ} \mathrm{S}-10^{\circ} \mathrm{N}, 120^{\circ} \mathrm{E}-80^{\circ} \mathrm{W}\right)$ with the variances they explain calculated from the 18 CMIP5 RCP4.5 simulations.

with change of the Hadley circulation, indicated by a high intermodel correlation coefficient of 0.49 .

The analyses presented so far indicate that the centennial warming in the central and eastern equatorial
Pacific in the CMIP5 simulations is related to the same feedback mechanisms that produce SST variability for the CP and EP types of El Niño. Given the fact that in both cases, the Bjerknes and WES feedback mechanisms
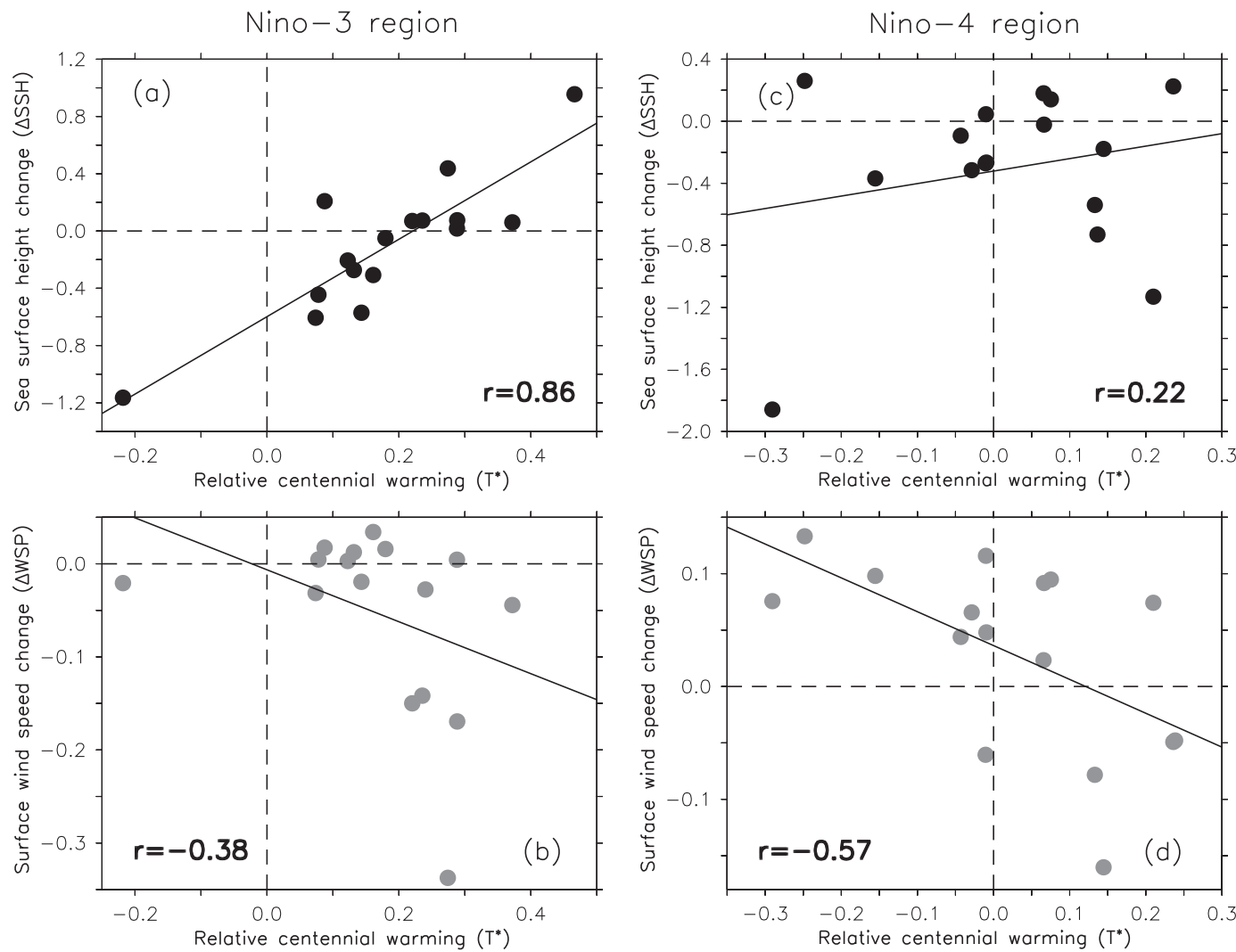

FIG. 7. Relations between the relative centennial warming and (a),(c) centennial changes in sea surface height and (b),(d) surface wind speed over the (left) Niño-3 and (right) Niño-4 regions calculated from the 18 CMIP5 simulations. 


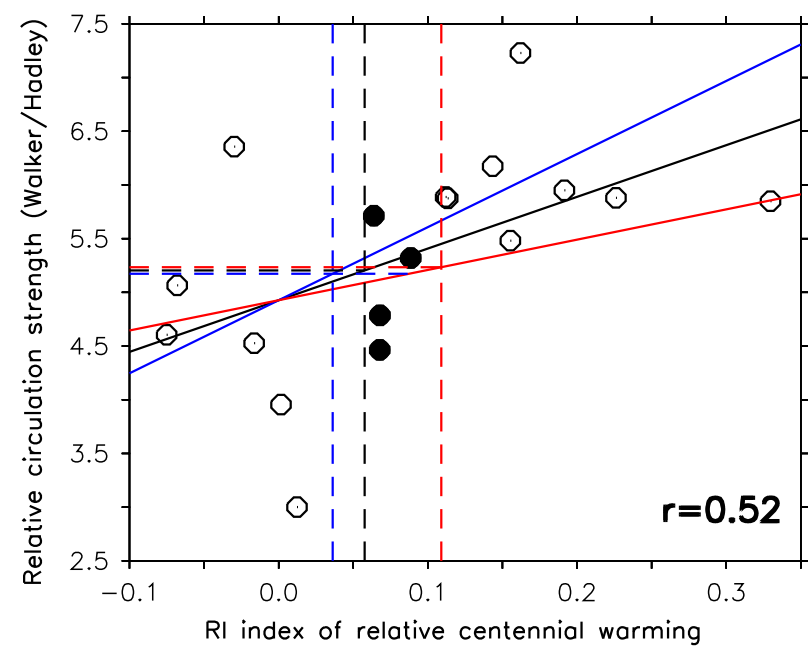

FIG. 8. Relation between the relative importance index $\left(\mathrm{K} \mathrm{K}^{-1}\right)$ of the centennial warming patterns and the relative strengths $\left(10^{-5} \mathrm{~m}^{2} \mathrm{~kg}^{-1}\right)$ of the mean Walker and Hadley circulations (2006-15) in the 18 CMIP5 RCP4.5 simulations. Dashed lines mark the relative circulation strength $\left[(5.2 \pm 0.03) \times 10^{-5} \mathrm{~m}^{2} \mathrm{~kg}^{-1}\right]$ determined from observed interannual SST variability (Fig. 4) and the corresponding most-likely RI index [0.058 (range 0.036$0.109) \mathrm{K} \mathrm{K}^{-1}$ ] projected by the regression line. Colored lines (colored dashed lines) indicate the uncertainty (standard deviation) of the regression (estimation). Solid dots represent the most-likely models with their RI indices falling within the uncertainty of the most-likely value.

are associated with the Walker and Hadley circulations, respectively, and the dominance of the type of El Niño is influenced by their relative strength (Yu et al. 2012), it is plausible that the location of the centennial warming in the equatorial Pacific is also influenced by the mean strengths of these two circulations. This hypothesis is tested in Fig. 8 by relating the relative circulation strength $(\bar{W} / \bar{H})$ produced by the 18 simulations during 2006-15 and the location of the relative centennial warming in the equatorial Pacific. To determine if the warming is located more in the EP or CP region, we calculate the difference between the absolute value of $T^{*}$ in the Niño-3 region (representing the EP) and that in the Niño-4 region (representing the $\mathrm{CP}$ ). This value is referred to as the relative importance (RI) index. Figure 8 shows a linear relationship between the RI index and $\bar{W} / \bar{H}$ among the 18 CMIP5 models: the larger the relative circulation strength a model produces, the larger the $\mathrm{RI}$ index its centennial warming has. The intermodel correlation coefficient is 0.52 and the regression reaches the $98 \%$ significance level. This relation indicates that the centennial warming locates more in the EP than the $\mathrm{CP}$ if the projected twenty-first century has a stronger mean Walker circulation than Hadley circulation, and vice versa. Therefore, the relative strengths of Walker and Hadley circulations can influence not only the El
Niño location but also the patterns of the centennial surface warming in the equatorial Pacific.

It is important to note that the relative circulation strength $(\bar{W} / \bar{H})$ is a common variable that affects the frequency ratio of the EP and CP El Niño and the location of the centennial warming in the equatorial $\mathrm{Pa}-$ cific. This variable can be utilized to link the EP-to-CP frequency ratio in Fig. 4 to the RI index in Fig. 8. Therefore, the observed El Niño statistics can be used to reduce the uncertainty in the centennial warming patterns. We first determine the EP-to-CP frequency ratio to be 1.0 near the beginning of the twenty-first century (1991-2010) from the HadISST dataset. We have tested the sensitivity of this ratio to time period and found it to be much weaker than the intermodel variability. Hence, this observed value is used to infer the relative circulation strength for the twenty-first century from the linear relation established in Fig. 4. Considering the uncertainty of the regression (color lines), this value is estimated to be $(5.2 \pm 0.03) \times 10^{-5} \mathrm{~m}^{2} \mathrm{~kg}^{-1}$. The best guess of $\bar{W} / \bar{H}$ is then applied to the linear relation in Fig. 8 to find the most-likely value of the RI index, which is $0.058 \mathrm{~K} \mathrm{~K}^{-1}$. With the error of regression in Fig. 8 compounded together with that in Fig. 4, it has an uncertainty range of $0.036-0.109 \mathrm{~K} \mathrm{~K}^{-1}$ (colored dashed lines in Fig. 8). There are four CMIP5 models whose simulations have RI indices within this range: ACCESS1.0, CCSM4, IPSLCM5A-LR, and IPSL-CM5A-MR. These models are considered to produce the most-likely RCP4.5 projections under the constraint of the observed El Niño activity.

These four most-likely projections of the relative centennial warming are averaged and compared with the 18-model mean in Fig. 9. We also compare the intermodel uncertainty between these two projections using their robustness, defined as the ratio of the mean (absolute value) divided by the intermodel spread (Ma and Xie 2013). Regions where this ratio is larger than one are considered robust and hatched. One can see that the most-likely projection (Fig. 9a) is robust over a larger area of the tropical Pacific than the 18-model mean (Fig. 9b), which indicates that the intermodel uncertainty is significantly reduced. In addition, we randomly drew four models and found that the robustness is unimproved (Fig. 9c) by simply reducing the number of models, suggesting that the most-likely models indeed share extraordinarily common features. The most-likely projection and 18-model mean agree in the southeastern subtropical Pacific where relatively weaker centennial warming $\left(T^{*}<0\right)$ is found (Figs. 9a,b). As for the equatorial Pacific, both projections exhibit an EP warming; however, the 18 -model mean is $64 \%$ stronger than the most-likely projection (measured by the Niño-3 


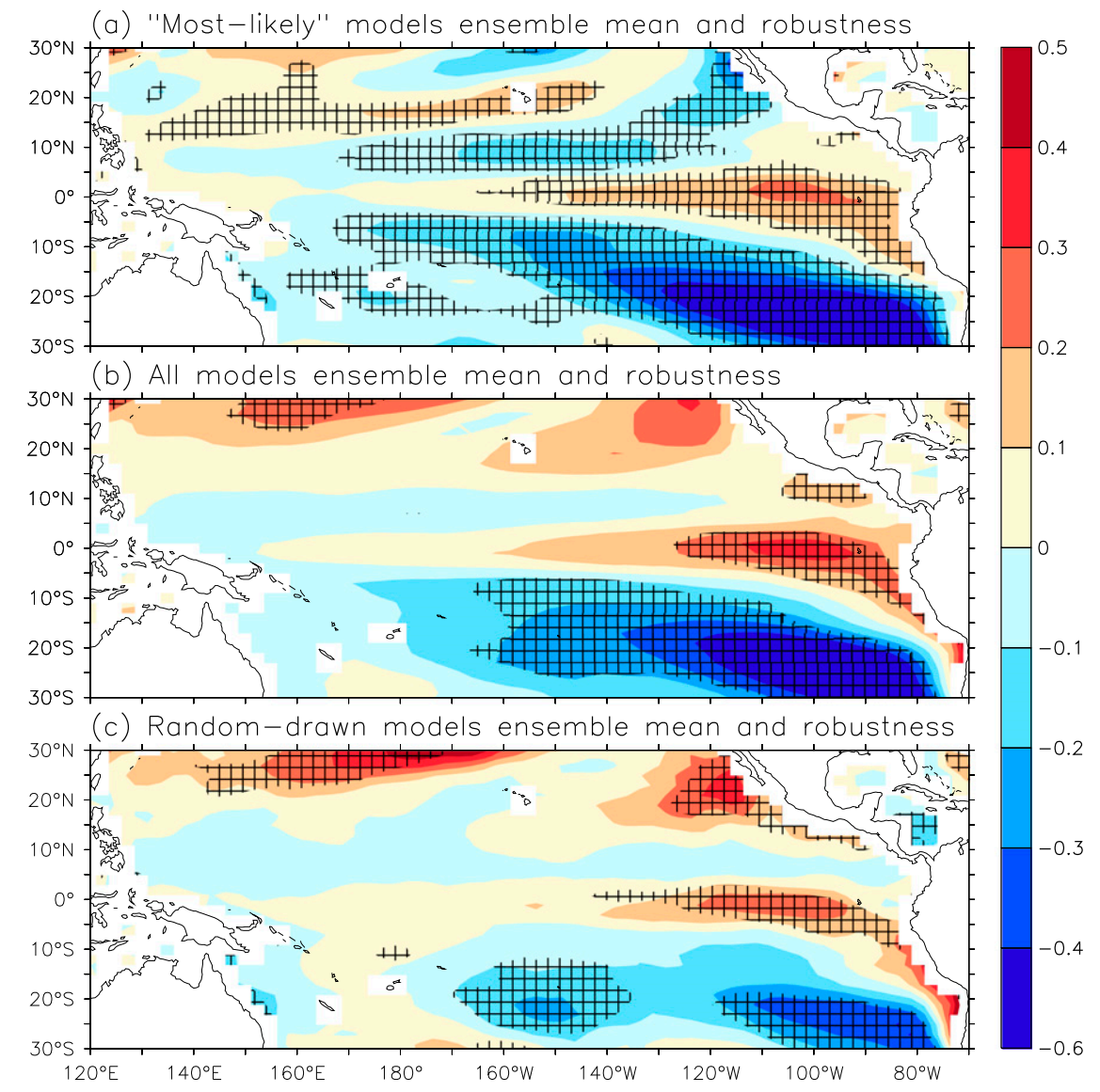

FIG. 9. Ensemble mean and robustness of tropical Pacific centennial warming patterns $\left(\mathrm{K} \mathrm{K}^{-1}\right.$ ) projected along RCP4.5 by (a) the four most-likely CMIP5 models, (b) all 18 models, and (c) four randomly drawn models. Robustness is defined as ratio of the ensemble mean (absolute value) over intermodel spread, and values $>1$ are hatched. The most-likely models are the ACCESS1.0, CCSM4, IPSL-CM5A-LR, and IPSL-CM5A-MR, based on the selection process described in Figs. 4 and 8. The randomly drawn models are the CNRM-CM5, HadGEM2-ES, INM-CM4, and MRI-CGCM3.

index). The two multimodel means disagree the most in the subtropical North Pacific. While the 18-model mean predicts stronger warming $\left(T^{*}>0\right)$ almost throughout the region, the most-likely projection shows a finer-scale fluctuating pattern. Two weaker-warming belts appear in the most-likely projection, sandwiching a strongerwarming belt extending from the U.S. West Coast across to the Hawaiian Islands.

\section{Conclusions and discussion}

The present study analyzes 18 CMIP5 RCP4.5 simulations to show that the centennial warming patterns in the equatorial Pacific can be influenced by the relative strengths of the Walker and Hadley circulations. A stronger Walker circulation is associated with stronger surface warming in the eastern equatorial Pacific via the Bjerknes feedback mechanism, while a stronger Hadley circulation is associated with stronger warming in the central equatorial Pacific through the WES feedback mechanism (the zonal advective feedback may also be at work). The influences of these two atmospheric circulations on the location of the centennial warming are shown to be similar to those found for the EP and CP types of El Niño. This similarity is obtained to develop a methodology to use the observed El Niño activity to constrain the estimate of the projections of the twentyfirst century warming patterns. Using the observed frequency ratio of the EP and CP El Niño near the beginning of the twenty-first century as the constraint, we determine that the "most likely" centennial warming patterns are characterized by weaker warming throughout the southeastern subtropical Pacific, stronger warming in the eastern equatorial Pacific, and alternating stronger and weaker warming in the subtropical North Pacific. The projection averaged from all 18 CMIP5 
models is consistent with the most-likely projection in the southeastern subtropical Pacific. However, it does not show the finer-scale warming fluctuation in the subtropical North Pacific and predicts stronger warming in the eastern equatorial Pacific. Caution should be exercised when using such unconstrained multimodel means to infer future warming patterns in these two regions. It is noteworthy that the relationship established in this study is only over the equatorial Pacific, so caution must be taken when applying to higher latitudes.

The constraining process established by Figs. 4 and 8 emphasizes the important role of the relative strengths of the Walker and Hadley circulations in linking interannual variability and global warming. In fact, one can make a scatterplot (not shown) and perform a regression directly between the EP-to-CP frequency ratio and the RI index. The intermodel correlation coefficient can reach 0.62 and the regression passes the $99.8 \%$ significance level. Not surprisingly, the observation-constrained most-likely models remain the same.

In the interannual time scale, the ratio of EP-to-CP El Niño is in frequency, while the ratio of strength of SST anomalies is used for the centennial time scale. This usage of two different variables should be valid, inferred from the following evidences. As mentioned before, the CP El Niño is reported to be more frequent recently. This trend may continue with anthropogenic global warming (Yeh et al. 2009) and, at the same time, the intensity of the CP El Niño might also increase (Kim and Yu 2012). This indicates that there is a positive correlation between EP-to-CP El Niño frequency and strength changes.

In this study, we do not focus on the relationship between SST and circulation changes because they are involved in the same feedback processes. There should be some environmental variable that sets the extents of the feedbacks (i.e., the relative mean circulation strength discussed here). One might argue that it seems unreasonable to constrain the estimate of the centennial warming with circulation strength influenced by it. Indeed, the change and/or mean ratio of the Walker (Hadley) circulation is as small as $7 \% \mathrm{~K}^{-1}\left(3 \% \mathrm{~K}^{-1}\right)$, indicating that the influence of $\bar{W} / \bar{H}$ is robust in the twenty-first century.

It should be pointed out that although the method developed in this study is exploratory in nature, the conclusion that the Walker and Hadley circulations can quantitatively link interannual variability and climate change can be useful in reducing uncertainties in climate projections.

Acknowledgments. We acknowledge various modeling groups for producing and providing their output, the PCMDI for collecting and archiving the CMIP5 multimodel dataset, the WCRP's WGCM for organizing the analysis activity, and the Office of Science, U.S. Department of Energy for supporting this dataset in partnership with the Global Organization for Earth System Science Portals. Three anonymous reviewers are appreciated for their constructive comments and suggestions. The Ferret program was used for analysis and graphics. This work is supported by NSF (Grant AGS-1233542) and NOAA (Grant NA11OAR4310102).

\section{REFERENCES}

Ashok, K., S. Behera, A. S. Rao, H. Weng, and T. Yamagata, 2007: El Niño Modoki and its possible teleconnection. J. Geophys. Res., 112, C11007, doi:10.1029/2006JC003798.

Bjerknes, J., 1969: Atmospheric teleconnections from the equatorial Pacific. Mon. Wea. Rev., 97, 163-172, doi:10.1175/ 1520-0493(1969)097<0163:ATFTEP >2.3.CO;2.

Held, I. M., and B. J. Soden, 2006: Robust responses of the hydrological cycle to global warming. J. Climate, 19, 5686-5699, doi:10.1175/JCLI3990.1.

Huang, P., S.-P. Xie, K. Hu, G. Huang, and R. Huang, 2013: Patterns of the seasonal response of tropical rainfall to global warming. Nat. Geosci., 6, 357-361, doi:10.1038/ngeo1792.

Kao, H.-Y., and J.-Y. Yu, 2009: Contrasting eastern-Pacific and central-Pacific types of ENSO. J. Climate, 22, 615-632, doi:10.1175/2008JCLI2309.1.

Kim, S. T., and J.-Y. Yu, 2012: The two types of ENSO in CMIP5 models. Geophys. Res. Lett., 39, L11704, doi:10.1029/ 2012 GL052006.

Kug, J.-S., F.-F. Jin, and S.-I. An, 2009: Two types of El Niño events: Cold tongue El Niño and warm pool El Niño. J. Climate, 22, 1499-1515, doi:10.1175/2008JCLI2624.1.

Larkin, N. K., and D. E. Harrison, 2005: On the definition of El Niño and associated seasonal average U.S. weather anomalies. Geophys. Res. Lett., 32, L13705, doi:10.1029/2005GL022738.

Lee, T., and M. J. McPhaden, 2010: Increasing intensity of El Niño in the central-equatorial Pacific. Geophys. Res. Lett., 37, L14603, doi:10.1029/2010GL044007.

Liu, Z., S. Vavrus, F. He, N. Wen, and Y. Zhong, 2005: Rethinking tropical ocean response to global warming: The enhanced equatorial warming. J. Climate, 18, 4684-4700, doi:10.1175/JCLI3579.1.

Lu, J., G. Chen, and D. Frierson, 2008: Response of the zonal mean atmospheric circulation to El Niño versus global warming. J. Climate, 21, 5835-5851, doi:10.1175/2008JCLI2200.1.

Ma, J., 2012: Dynamics and uncertainties of global warming patterns: Sea surface temperature, precipitation, and atmospheric circulation. Ph.D. dissertation, University of Hawai'i at Mānoa, $126 \mathrm{pp}$.

_ , and S.-P. Xie, 2013: Regional patterns of sea surface temperature change: A source of uncertainty in future projections of precipitation and atmospheric circulation. J. Climate, 26, 2482-2501, doi:10.1175/JCLI-D-12-00283.1.

,$- \ldots$, and Y. Kosaka, 2012: Mechanisms for tropical tropospheric circulation change in response to global warming. J. Climate, 25, 2979-2994, doi:10.1175/JCLI-D-11-00048.1.

Rayner, N. A., D. E. Parker, E. B. Horton, C. K. Folland, L. V. Alexander, D. P. Rowell, E. C. Kent, and A. Kaplan, 2003: Global analyses of sea surface temperature, sea ice, and night marine air temperature since the late nineteenth century. J. Geophys. Res., 108, 4407, doi:10.1029/2002JD002670. 
Thomson, A. M., and Coauthors, 2011: RCP4.5: A pathway for stabilization of radiative forcing by 2100 . Climatic Change, 109, 77-94, doi:10.1007/s10584-011-0151-4.

Vecchi, G. A., and B. J. Soden, 2007: Effect of remote sea surface temperature change on tropical cyclone potential intensity. Nature, 450, 1066-1070, doi:10.1038/nature06423.

—, A. Clement, and B. J. Soden, 2008: Examining the tropical Pacific's response to global warming. Eos, Trans. Amer. Geophys. Union, 89, 81-83, doi:10.1029/2008EO090002.

Vimont, D. J., D. S. Battisti, and A. C. Hirst, 2001: Footprinting: A seasonal connection between the tropics and mid-latitudes. Geophys. Res. Lett., 28, 3923-3926, doi:10.1029/2001GL013435.

- J. M. Wallace, and D. S. Battisti, 2003: Seasonal footprinting mechanism in the Pacific: Implications for ENSO. J. Climate, 16, 2668-2675, doi:10.1175/1520-0442(2003)016<2668: TSFMIT $>2.0 . \mathrm{CO} ; 2$.

_ M. Alexander, and A. Fontaine, 2009: Midlatitude excitation of tropical variability in the Pacific: The role of thermodynamic coupling and seasonality. J. Climate, 22, 518-534, doi:10.1175/2008JCLI2220.1.

Xie, S.-P., and S. G. H. Philander, 1994: A coupled ocean-atmosphere model of relevance to the ITCZ in the eastern Pacific. Tellus, 46A, 340-350, doi:10.1034/j.1600-0870.1994.t01-1-00001.x.
— C. Deser, G. A. Vecchi, J. Ma, H. Teng, and A. T. Wittenberg, 2010: Global warming pattern formation: Sea surface temperature and rainfall. J. Climate, 23, 966-986, doi:10.1175/ 2009JCLI3329.1.

Yeh, S.-W., J.-S. Kug, B. Dewitte, M.-H. Kwon, B. P. Kirtman, and F.-F. Jin, 2009: El Niño in a changing climate. Nature, 461, 511514, doi:10.1038/nature08316.

Yu, J.-Y., and H.-Y. Kao, 2007: Decadal changes of ENSO persistence barrier in SST and ocean heat content indices: 1958-2001. J. Geophys. Res., 112, D13106, doi:10.1029/ 2006JD007654.

_ - and S. T. Kim, 2011: Relationships between extratropical sea level pressure variations and the central Pacific and eastern Pacific types of ENSO. J. Climate, 24, 708-720, doi:10.1175/ 2010JCLI3688.1.

— H.-Y. Kao, and T. Lee, 2010: Subtropics-related interannual sea surface temperature variability in the central equatorial Pacific. J. Climate, 23, 2869-2884, doi:10.1175/ 2010JCLI3171.1.

_- M.-M. Lu, and S. T. Kim, 2012: A change in the relationship between tropical central Pacific SST variability and the extratropical atmosphere around 1990. Environ. Res. Lett., 7, 034025, doi:10.1088/1748-9326/7/3/034025. 